European Journal of Probation

University of Bucharest

www.ejprob.ro

Vol. 5, No.1, 2013, pp $65-85$

ISSN: $2006-2203$

\title{
Do intervention plans meet criteria for effective practice to reduce recidivism? How probation officers forget about social capital and basic needs
}

\author{
Jacqueline Bosker \\ Cilia Witteman \\ Jo Hermanns ${ }^{1}$
}

\begin{abstract}
The increased use of instruments for assessing risks and needs in probation should lead to intervention plans that meet the criteria for effective practice. An analysis of 300 intervention plans from the Dutch probation service showed that the match between the assessed criminogenic needs and the goals and interventions in the intervention plan is fairly low. It was also found that the so-called risk principle is not fully applied by probation officers. In addition, personal goals that the offender values are often not taken fully into account. Finally, the intervention plans have a strong focus on improving human capital, while improving social capital and basic needs often is not part of the intervention plans, even if they were assessed as dynamic criminogenic needs.
\end{abstract}

Keywords: Intervention plan - Probation - Decision making - Human capital - Social capital R-N-R model

\section{Introduction}

Intervention plans form the backbone of offender supervision and describe the goals and interventions that should help offenders stop reoffending (Bonta et al. 2008; Healey 1999). An intervention plan may also be called a supervision plan, case management plan, risk management

\footnotetext{
${ }^{1}$ Jacqueline Bosker (researcher at the University Applied Sciences, Utrecht, The Netherlands). Correspondence concerning this article should be addressed to Jacqueline Bosker, Research Centre for Social Innovation, University of Applied Sciences, Heidelberglaan 7, 3584 CS Utrecht, the Netherlands; e-mail: jacqueline.bosker@ hu.nl.

Cilia Witteman (professor at the department of Clinical Psychology of the Behavioural Science Institute at the Radboud University Nijmegen, The Netherlands)

Jo Hermanns (professor at the Faculty of Social and Behavioural Sciences of the University of Amsterdam and lecturer at the University of Applied Sciences, Utrecht, The Netherlands)
} 
plan or sentence plan. In this article we use the term intervention plan to refer to a plan that consists of all the conditions, interventions, restrictions, control instruments and other activities by probation, other organizations and the offender, in order to reduce the risks of recidivism and harm. Interventions can entail behavioural training, psychological treatment, practical aid and support. In general, intervention plans focus on managing safety, modifying behaviour, and improving basic needs. Probation services use intervention plans to advise the court via a presentence report or to describe a sentence plan for prisoners or offenders who are under community supervision.

Research regarding effective practice has demonstrated clearly that intervention plans should be based on structured risk and needs assessment (Bonta 2002; Campbell et al. 2007; Dowden and Andrews 1999; Hanson et al. 2007). First, the reliability and validity of assessments can be improved with the use of a structured assessment instrument (Bonta 2002; Grove et al. 2000). Second, the use of structured risk and needs assessment should lead to intervention plans that meet the criteria of effective practice (Andrews and Bonta 2006; Douglas et al. 2001; Healey 1999). However, evidence suggests that in practice the coherence between the risk and needs assessment and the intervention plan is not a straightforward matter. In a study of offender supervision for example, Bonta and colleagues found that much of the information obtained from the assessment was not used in the intervention plan (Bonta et al. 2008). Vieirra and colleagues investigated the match between the assessed needs and the services received through probation. In a sample of 122 cases of young offenders, the general needs - probation match turned out to be only 35\% (Vieira et al. 2009). The authors found a moderate correlation between needs probation match and recidivism $(\mathrm{r}=-0.48, \mathrm{p}<0.001)$. Having only a few needs met, young offenders were more likely to reoffend both earlier and more frequently. These results confirm that a good match between the assessment, the intervention plan, and the interventions that are delivered is important.

In contrast to the extensive body of research regarding structured risk and needs assessment, studies of intervention plans in the field of offender rehabilitation are scarce. To fill this gap, the aim of the current study was to evaluate the extent to which intervention plans that are based on an instrument for structured risk assessment actually meet the criteria of effective practice in probation. The seven criteria that were formulated to evaluate the quality of the intervention plans are described in the next paragraph. The Dutch instrument for risk and needs assessment is described in the methods section. The results are presented in a subparagraph per criterion. Limitations and future directions are discussed.

\section{Criteria for effective intervention plans}

Both research on what works to reduce recidivism and research on desistance from crime afford general knowledge about what a good intervention plan should look like. Stable support has been found for the so called risk - needs - responsivity (R-N-R) model. This model consists of three principles that, when used together, are expected to have substantial impact on the reduction of recidivism (Andrews and Bonta 2006; Bonta and Andrews 2010). The risk principle states that the level of supervision and intensity of the interventions should match the risk of recidivism. The higher the risk of recidivism, the more intensive the intervention plan should be (Lowenkamp et al. 2006). The needs principle states that interventions should focus on the needs and problems that are related to the criminal behaviour. An extensive body of research has 
revealed criminogenic needs such as antisocial personality, antisocial attitudes, antisocial relations, a history of anti-social behaviour, poor quality of the relations with partner and family, lack of education and work, and drug- and alcohol abuse (Andrews and Bonta 2006). The responsivity principle states that in general, social learning and cognitive behavioural strategies have proven to be the most effective in reducing recidivism (Andrews and Bonta 2010; Hanson et al. 2009; Jolliffe and Farrington 2007). On an individual level, the responsivity principle states that interventions should match the learning styles, abilities, motivation and limitations of offenders (Bonta and Andrews 2010).

The growing body of research about desistance from crime has led to additional insights about effective offender supervision. This research focuses on the life-courses of offenders and on the question why and how some offenders persist and others desist from criminal behaviour (Farral 2002; Maruna and LeBel 2010). Research on desistance from crime has shown that improving the so-called social capital of offenders can be an essential part of an effective rehabilitation process (LeBel et al. 2008; McNeill and Weaver 2010; Serin and Lloyd 2009; Smith and Vanstone, 2002). The concept of social capital was introduced by Coleman (1988) and refers to characteristics of social relationships between individuals that generate obligations and expectations, information, and norms. Obligations and expectations refer to social structures with mutual support. Social relations can provide all sorts of information that can be helpful in achieving one's interests. Finally, social structures can have strong norms that lead to rewards (e.g. friendship) for positive behaviour and sanctions (e.g. disapproval) for negative behaviour. Besides family and friends, social capital can be found in relations in the neighbourhood, at work or in church. Changes in situational and structural life circumstances of offenders - e.g. a good marriage or a stable job - can increase social capital and thus support desistance and improve motivation for change (Farral 2002; Laub and Sampson 2003). Therefore, intervention plans should not only focus on improving the skills and knowledge (e.g. education that is supportive for getting a job) of an individual, so-called human capital, but should also pay attention to the social context that offenders are in and the way this context influences their behaviour. Helping offenders to create a supportive network and to let go of an antisocial network can be an effective strategy to reduce recidivism. The concept of social capital for effective offender rehabilitation is not included in, but does not contradict, the R-N-R model. Some of the criminogenic needs in the R-N-R model refer to social capital, for example the relationship with friends and work.

In intervention plans, it is important to include goals that can be achieved. In different theories and methods for behavioural change, it is found that working with goals appears to be effective in a change process. Goals can help people focus, they energize and affect persistence (Locke and Latham 2002). In order to have this effect, goals must be specific. Both for the offender and the probation officer it must be clear what to work on. Moreover, goals can effectively support a change process if they are formulated as something to be approached, instead of as something to be avoided (Emmons 1996). Approach goals are formulated in terms of what must be achieved, whereas avoidance goals are formulated as situations that must be avoided or behaviour that must be unlearned. Both in research about addiction treatment and relapse prevention of sexual offenders it was found that people who work on approach goals relapse less frequently and are more engaged in treatment than people who work on avoidance goals (Mann et al. 2004). 
In a probation context, goals are often formulated by the probation officer. Based on the risk and needs assessment, the probation officer decides which needs should be addressed and subsequently, what goals should be reached regarding the assessed needs. However, in literature about desistance from crime the importance of working on the offenders' goals is emphasized, because it helps motivate the offenders for change and to commit themselves to the intervention plan (Ward and Maruna 2007). Agreement on goals is also considered to be an important characteristic of an effective working alliance, and therefore of an effective change process (McNeill and Whyte 2007). Therefore, making offender goals and probation goals explicit, and integrating offender goals in the intervention plan, may be expected to have a positive impact on the effectiveness of probation services.

Based on the research we summarised here, seven criteria for an effective intervention plan were formulated to be used in our study of the intervention plans (see Table 1). Of course, these criteria do not cover all there is to say about effective practice. There are some principles of effective offender supervision that we have not mentioned here, such as building a good working alliance, the use of evidence-based interventions, and strengthening protective factors.

Table 1: Criteria for an effective intervention plan used in this study

1. The intervention plan targets the dynamic criminogenic needs.

2. Goals match the dynamic criminogenic needs.

3. Interventions match the dynamic criminogenic needs

4. The intensity of the intervention plan matches the risk of recidivism.

5. The intervention plan contains specific goals.

6. The goals are formulated as approach goals, not as avoidance goals.

7. The intervention plan contains goals that are important for the offender.

\section{Methods}

Risk and needs assessment

The Dutch probation service uses an instrument for structured risk assessment called the Recidive Inschattings Schalen (recidivism assessment scales, RISc) (Hildebrand 2010). RISc is based on the English and Welsh Offender Assessment System (OASys) (Home Office 2002). RISc contains items about the following 12 criminogenic needs: (1) offending history, (2) current offence, (3) accommodation, (4) education and employment, (5) income and financial management, (6) relationships with partner, family and relatives, (7) relationships with friends and acquaintances, (8) drug abuse, (9) alcohol abuse, (10) emotional well-being, (11) thinking and behaviour, and (12) attitudes. Each criminogenic need is assessed on a scale that contains a number of risk items which are scored as 0 (no problems), 1 (some problems), or 2 (significant problems). Table 2 shows the number of items in each scale and some examples of items. Criminogenic needs can be either static, meaning that they cannot change or change in only one direction (e.g. age), or dynamic, meaning they can change (Bonta, 2002). Scales 3 through 12 represent dynamic criminogenic needs. Some of the RISc scales that represent a dynamic criminogenic need also contain one or two static items, describing problems of the past.

The total score of the items in a RISc scale represents the severity of that criminogenic need. For every scale, cut-off scores are used to indicate whether the specific criminogenic need is considered to be relevant in an individual case or not. Taking into account the varying strengths 
of the correlation between the criminogenic needs and recidivism, the raw total score of the scales are converted into weighted scores. The weights are based on the weights of OASys and on a review of studies about the predictive value of risk factors (Hildebrand 2010). The sum of the weighted scale scores represents the risk of recidivism and is grouped into the following four categories: low risk, moderate-low risk, moderate-high risk and high risk. The internal consistency of the scales was found to be moderate to good for most scales ( $\alpha$ between 0.61 and 0.88) (Van der Knaap et al. 2007). The inter-rater agreement of the risk scales and total score was found to be moderate to substantial (Tinsley and Weiss' value T between 0.43 and 0.78 ) (Van der Knaap et al. 2010). The predictive validity for general recidivism of RISc is sufficient for both men $\left(\mathrm{AUC}^{2}=0.70\right)$ and women $(\mathrm{AUC}=0.68)$ (Van der Knaap and Alberda 2009). The items in RISc are scored by the probation officer. In addition, the offender performs a selfassessment to provide his or her opinion of the actual problems and to emphasize priorities.

Based on the risk assessment, the probation officer formulates an intervention plan. In this study, we focused on the following three domains of the intervention plan: (1) a description of the criminogenic needs that are perceived as relevant and therefore must be influenced, (2) the goals describing the desired behavioural change or change of living circumstances, and (3) the interventions needed to realize the change.

\footnotetext{
${ }^{2}$ The area under the curve (AUC) is a generally used statistical measure for the predictive validity of risk assessment tools. It describes the probability that a randomly chosen recidivist will score higher on the instrument than a randomly chosen non-recidivist. In general, an AUC value of 0.70 to 0.74 is considered moderate and values above 0.75 are considered good (De Vogel 2005).
} 
Table 2: Overview RISc scales, number of items in each scale and sample items for each scale RISc scales Number Sample items

of items

\begin{tabular}{|c|c|c|c|}
\hline $1-2$ & $\begin{array}{l}\text { Offending History and } \\
\text { Current Offence }\end{array}$ & 8 & $\begin{array}{l}\text { - Number of convictions as a } \\
\text { juvenile } \\
\text { - } \begin{array}{l}\text { Previous noncompliance with } \\
\text { probation conditions }\end{array}\end{array}$ \\
\hline 3 & Accommodation & 4 & $\begin{array}{l}\text { - } \text { Current housing } \\
\text { - Suitability and permanency of } \\
\text { current housing }\end{array}$ \\
\hline 4 & Education and Employment & 7 & $\begin{array}{l}\text { - Level of training and } \\
\text { certificates obtained } \\
\text { - } \text { Current work situation }\end{array}$ \\
\hline 5 & $\begin{array}{l}\text { Income and Financial } \\
\text { Management }\end{array}$ & 4 & $\begin{array}{l}\text { - Main source of income } \\
\text { - Current financial situation }\end{array}$ \\
\hline 6 & $\begin{array}{l}\text { Relationships with Partner, } \\
\text { Family, Relatives }\end{array}$ & 5 & $\begin{array}{l}\text { - Quality of current relationship with } \\
\text { partner, family, and other relatives } \\
\text { - Family member has criminal record }\end{array}$ \\
\hline 7 & $\begin{array}{l}\text { Relationships with Peers and } \\
\text { Acquaintances }\end{array}$ & 4 & $\begin{array}{l}\text { - Quality of relationship with } \\
\text { friends and acquaintances } \\
\text { - Manipulates friends and } \\
\text { acquaintance }\end{array}$ \\
\hline 8 & Drug Abuse & 6 & $\begin{array}{l}\text { - Drugs are at the forefront in } \\
\text { the person's life } \\
\text { - Criminal behavior and drug } \\
\text { use are linked }\end{array}$ \\
\hline 9 & Alcohol Abuse & 5 & $\begin{array}{l}\text { - Current alcohol use is } \\
\text { problematic } \\
\text { - Criminal behavior and alcohol } \\
\text { use are linked }\end{array}$ \\
\hline 10 & Emotional Well-being & 5 & $\begin{array}{l}\text { - } \quad \text { Mental health problems } \\
\text { - } \quad \text { Self-destructive behavior }\end{array}$ \\
\hline 11 & Thinking and Behavior & 8 & $\begin{array}{l}\text { - Impulsivity } \\
\text { - Problem handling }\end{array}$ \\
\hline 12 & Attitudes & 5 & $\begin{array}{l}\text { - Procriminal attitude } \\
\text { - Willingness to change }\end{array}$ \\
\hline & RISc total & 61 & \\
\hline
\end{tabular}




\section{Procedure}

Data were gathered from probation files that included a risk assessment and an intervention plan. Permission for using the files was given by the probation service. Part of the necessary data were delivered by the probation service in a database containing all item scores, scale scores and the total score of the risk assessment. The other necessary information (the self-assessments and relevant parts of the intervention plan) were coded by hand from the files, using a coding manual. The researcher and her assistants declared confidentiality and file information was processed anonymously. Four research assistants helped to make an overview of the goals and interventions in the intervention plans. The researcher (the first author) coded the files.

\section{Sample}

The sampling pool consisted of a cohort of risk assessments (including an intervention plan) that had preceded supervision in the framework of a suspended prison sentence. First, all supervisions with a suspended prison sentence for unique offenders that started in the period between January 1, 2010 and March 31, 2010 were selected $(\mathrm{N}=1865)$. Subsequently, to these cases risk assessments were matched that represented the situation of the offender at the start of the supervision. We decided to include assessments that were completed between six months before the start of the supervision and three months after the start of the supervision. This resulted in a sampling pool of 821 cases. Another 85 cases were removed from the sampling pool because the offender denied the offence during the assessment, and when an offender denies the offence and has not been sentenced yet, probation officers often do not formulate an intervention plan. The final sampling pool consisted of 736 cases. From this pool, a sample of 300 cases was selected at random.

We tested whether these 300 cases were representative for the total population of offenders under supervision in connection with a suspended prison sentence in that period. The offenders in the sample did not differ from the total population with respect to the number of men and women, the average age, and the risk of recidivism. Small differences were found between the sample and all offenders regarding their ethnic background.

In the sample, $90 \%$ was male and $10 \%$ female. The average age of the offenders was 34 years $(\mathrm{SD}=12$, range $18-74)$. A majority of the offenders $(64 \%)$ had committed a violent offence, $24 \%$ a property offence, $8 \%$ a drug offence, $3 \%$ a sexual offence and $2 \%$ other offences ${ }^{3}$. Based on the sum score of RISc, the offenders are divided over the risk categories as follows: 17\% low risk, 31\% moderate-low risk, 26\% moderate-high risk, 25\% high risk. The number of dynamic criminogenic needs (in this study we defined 9 dynamic criminogenic needs, see variable construction) varies from 0 to 9 , with an average of $5(\mathrm{SD}=2)$.

\section{Variable construction}

Most of the items were recoded to be suitable for analysis, as follows.

- Dynamic criminogenic needs considered present: RISc contains 10 dynamic criminogic needs (scale 3 to 12). To determine whether a dynamic criminogenic need is present or absent in an individual case, the RISc cut-off scores are used. Some criminogenic needs can score above the cut-off point based only on the scores of items concerning problems in the

\footnotetext{
${ }^{3}$ The sum of these percentages is larger than $100 \%$ due to rounding the decimal places.
} 
- past. For example, two of the six items in the section on drug abuse regard drug misuse in the past. High scores on these items can lead to a summed score above the cut-off score of this section. However, if there is no actual problem, no intervention is expected. Therefore, in this study a dynamic criminogenic need is considered present if it scores above the cut-off score and if there is an actual problem (present $=1$, absent $=0$ ).

- Emotional well-being: The RISc cut-off score for the criminogenic need emotional wellbeing is so high that some offenders with psychological problems do not reach this score. Therefore the cut-off score was adjusted in such a way that emotional well-being is considered present if offenders have actually diagnosed psychiatric problems or a combination of actual problems on this scale.

- Addiction: Some probation officers do not distinguish drug and alcohol abuse in the intervention plans, yet formulate goals on addiction. Therefore, the criminogenic needs for drug abuse and alcohol abuse were combined into one criminogenic need drug/alcohol abuse, resulting in 9 dynamic criminogenic needs in this study.

- Goal clusters: To examine the relation between the dynamic criminogenic needs and the goals in the intervention plan, the goals were recoded into clusters that match the dynamic criminogenic needs. Some of the goals (14\%) could not be clustered into a category that matches a dynamic criminogenic need and are not included in the analysis. These goals were not related to a specific need (e.g. no re-offence ), were too vague (e.g. change behaviour) or described an intervention instead of a desired change on a criminogenic need (e.g. attend treatment).

- Interventions: The interventions were recoded into clusters that match the criminogenic needs and the clustered goals. Some interventions may influence a criminogenic need, but the match is not obvious. For example, clinical psychological treatment is obviously related to emotional well-being and thinking and behaviour, but during treatment, problems with relations might also be addressed. The files do not specifically describe what is or what should be done during treatment. Therefore, the match between interventions and dynamic criminogenic needs is scored on a scale from 0 to 2: the intervention does not address $(0)$, may address (1), or does address (2) a specific criminogenic need.

- Goals offender: The self-assessment is used as an indicator of the goals of the offender. In the self-assessment, information is gathered regarding the problems that are important for the offender and regarding his or her priorities. The issues that are a problem or a priority for the offender are considered to be goals of the offender. These issues were clustered in the same categories as the dynamic criminogenic needs, goals and interventions. In 230 of the 300 cases a self-assessment was available. Reasons that probation officers describe for the absence of the self-assessment are: too difficult for the offender (9), no time (12), language problems offender (9), not necessary (15), forgotten (7), other reasons (6), no reason described (12).

Clustering the goals and interventions was done with the help of three experienced officers of the probation service. As a first step, they clustered the goals and interventions independently. Differences were discussed, and a final clustering was based on consensus.

\section{Analyses}

The aim of this study was to describe whether intervention plans that are based on an instrument for structured risk assessment meet the seven criteria of effective practice in probation (described in Table 1). To describe the extent to which the intervention plans target the criminogenic needs (criterion 1), goals match the criminogenic needs (criterion 2), interventions match the 
criminogenic needs (criterion 3) and intervention plans contain goals that are important for the offender (criterion 7), descriptive analyses (frequencies) are used. Subsequently, regarding criterion 1 the match is described as the proportion of offenders with a present criminogenic need (sum score of the scale is above the cut-off score and there is an actual problem) that is indicated as a need that should be targeted. The same is done for criterion 2, 3 and 7, using the goals and interventions in the intervention plan. To measure the extent to which the intensity of the intervention plan matches the risk of recidivism (criterion 4), Spearman correlation is used. Whether the goals are concrete and formulated as approach goals (criterion 5 and 6) is analysed by measuring the mean scores of the goals of the 300 intervention plans per goal cluster.

\section{Results}

Intervention plan targets dynamic criminogenic needs

The extent to which intervention plans target dynamic criminogenic needs (criterion 1) is shown in Table 3. When assessed as present (above cut-off score and actual problem), the dynamic criminogenic needs are perceived by the probation officers as being relevant to be targeted in a majority of the plans (match $57-88 \%$ ). This match differs between criminogenic needs. When present, probation officers decide to target problems with cognitive skills, addiction, attitude, and emotional well-being in $75-88 \%$ of the cases. The match is relatively low for practical and contextual needs such as accommodation, friends, education and work, and finance. For none of the assessed dynamic criminogenic needs, the match is $100 \%$.

Describing that a specific criminogenic need should be targeted, does not mean that the need actually is targeted. To get a clearer picture about the actual needs that are targeted in the intervention plans, we must look at the goals and interventions. The following paragraphs describe the match between the assessed criminogenic needs and the goals and interventions in the intervention plans. 
Table 3: Match between assessed criminogenic needs and criminogenic needs probation officers intend to target in the intervention plans $(N=300)$

\begin{tabular}{lllll}
\hline $\begin{array}{l}\text { Dynamic } \\
\text { criminogenic need }\end{array}$ & $\begin{array}{l}\text { Above cut-off } \\
\text { score RISc }\end{array}$ & $\begin{array}{l}\text { Targeted } \\
\text { Yes }\end{array}$ & No & \\
\hline Cognitive skills & 282 & 249 & 33 & $88 \%$ \\
Addiction & 186 & 159 & 27 & $85 \%$ \\
Attitude & 143 & 110 & 22 & $77 \%$ \\
Emotional well-being & 191 & 144 & 47 & $75 \%$ \\
Partner/family & 181 & 132 & 49 & $73 \%$ \\
Finance & 132 & 80 & 52 & $61 \%$ \\
Education/work & 186 & 106 & 80 & $60 \%$ \\
Friends & 124 & 74 & 50 & $60 \%$ \\
Accommodation & 115 & 66 & 49 & $57 \%$
\end{tabular}

${ }^{\mathrm{T}} \mathrm{RISc}=$ Recidivism Assessment Scale

${ }^{2}$ In this and subsequent tables, Match $=(\#$ targeted $/$ \# above cut-off score $) \times 100$

Goals match the dynamic criminogenic needs

The second criterion is whether the goals in the intervention plan match the dynamic criminogenic needs. Table 4 shows whether a goal was formulated with regard to the assessed criminogenic needs. The match between the goals and dynamic criminogenic needs was relatively low. The goals target the assessed criminogenic needs in more than $50 \%$ of the cases only for addiction and cognitive skills. With respect to basic needs (accommodation, education and work, finance), social relationships, attitude and emotional well-being, no goal is formulated in a majority of the cases in which the criminogenic need was assessed as being present. A comparison of Tables 3 and 4 shows that the perceived relevance of the criminogenic needs has a better match with the assessed criminogenic needs than the goals. Apparently, probation officers often define a criminogenic need as relevant, but they do not formulate a goal with respect to this specific need. 
Table 4: Match between assessed criminogenic needs and goals in the intervention plans $(N=$ 300)

\begin{tabular}{lllll}
\hline $\begin{array}{l}\text { Dynamic criminogenic } \\
\text { need }\end{array}$ & $\begin{array}{l}\text { Above cut-off } \\
\text { score RISc }\end{array}$ & $\begin{array}{l}\text { Goal } \\
\text { Yes }\end{array}$ & No & Match \\
\hline Addiction & 186 & 119 & 67 & $64 \%$ \\
Cognitive skills & 282 & 162 & 120 & $57 \%$ \\
Education/work & 186 & 89 & 97 & $48 \%$ \\
Finance & 132 & 59 & 73 & $45 \%$ \\
Emotional well-being & 191 & 81 & 110 & $42 \%$ \\
Accommodation & 115 & 48 & 67 & $42 \%$ \\
Friends & 124 & 43 & 81 & $35 \%$ \\
Partner/family & 181 & 44 & 137 & $24 \%$ \\
Attitude & 143 & 22 & 121 & $15 \%$ \\
\hline
\end{tabular}

Interventions match the dynamic criminogenic needs

The third criterion for determining the quality of an intervention plan is whether the interventions in the plan match the dynamic criminogenic needs. As described in the Methods, this match is coded in the following three categories: no match, possible match, and good match. The match between the assessed criminogenic needs and the interventions differs per criminogenic need (see Table 5). 
Table 5: Match between assessed criminogenic needs and interventions in the intervention plans

\begin{tabular}{|c|c|c|c|c|}
\hline \multirow{2}{*}{$\begin{array}{l}\text { Dynamic } \\
\text { need }\end{array}$} & \multirow{2}{*}{$\begin{array}{l}\text { Above cut-off } \\
\text { score RISc }\end{array}$} & \multicolumn{3}{|c|}{ Intervention } \\
\hline & & No match & Possible match & Good match \\
\hline Cognitive skills & 282 & $2 \%$ & $26 \%$ & $72 \%$ \\
\hline Emotional well-being & 191 & $16 \%$ & $20 \%$ & $63 \%$ \\
\hline Attitude & 143 & $3 \%$ & $37 \%$ & $60 \%$ \\
\hline Addiction & 186 & $3 \%$ & $39 \%$ & $58 \%$ \\
\hline Partner/family & 181 & $2 \%$ & $41 \%$ & $57 \%$ \\
\hline Education/work & 186 & $14 \%$ & $61 \%$ & $25 \%$ \\
\hline Accommodation & 115 & $7 \%$ & $61 \%$ & $23 \%$ \\
\hline Finance & 132 & $15 \%$ & $72 \%$ & $13 \%$ \\
\hline Friends & 124 & $19 \%$ & $82 \%$ & $0 \%$ \\
\hline
\end{tabular}

A relatively good match is found for cognitive skills. When a lack of cognitive skills were assessed as a dynamic criminogenic need, in $72 \%$ of the cases the intervention plan contained an intervention that addresses this need. With respect to emotional well-being, attitude, addiction and relationship with partner or family, 57 - 63\% of the intervention plans contained an intervention that addresses these needs when assessed as being present. With respect to basic needs (education and work, accommodation, and finance), in a large majority of cases no good match was found between the assessed criminogenic needs and the interventions (although these cases often have interventions in the plan that might match these problems). The percentage of cases in which no match was found between the assessed criminogenic needs and the interventions is small $(2-19 \%)$. Most of the intervention plans contain interventions that can influence the assessed criminogenic needs. The highest percentage of 'no match' was found for the criminogenic needs emotional well-being, education and work, finance, and friends.

Intensity intervention plan matches risk of recidivism

Based on studies regarding effective practice, low-risk cases should have low intensity intervention plans, and high-risk cases should have high intensity intervention plans (the risk principle) (Lowenkamp et al. 2006). Table 6 shows the match between the intensity of the intervention plans and the risk of recidivism (criterion 4). In this study, half of the plans have a low intensity, meaning that only one behavioural program or low intensive treatment is delivered. Low-risk cases often have low intensity intervention plans. In cases with a moderatelow, moderate-high or high risk of recidivism, the intensity of the intervention plans diverges from very low to very high. In these three risk levels, most intervention plans are either low- or 
high-intensity, and in all three risk levels, low-intensity intervention plans are over-represented. In high-risk cases, most intervention plans are low-intensity, although a moderate to very high intensity is found in a substantial number of high-risk cases. Overall, there is a low but significant correlation between the risk of recidivism and the intensity of the intervention plans ( $\mathrm{r}$ $=0.22 ; \mathrm{p}<0.01)$, meaning that the risk principle is employed rather poorly.

Table 6: Match between the risk of recidivism and the intensity of an intervention plan

\begin{tabular}{|c|c|c|c|c|c|}
\hline \multirow{2}{*}{$\begin{array}{l}\text { Intensity } \\
\text { intervention } \\
\text { plan }\end{array}$} & \multicolumn{4}{|c|}{ Risk recidivism } & \multirow[t]{2}{*}{ Total } \\
\hline & Low & Moderate low & Moderate high & High & \\
\hline Very low & 1 & 7 & 8 & 4 & 20 \\
\hline Low & 42 & 46 & 35 & 26 & 149 \\
\hline Moderate & 3 & 9 & 8 & 17 & 37 \\
\hline High & 5 & 25 & 20 & 15 & 65 \\
\hline Very high & 1 & 6 & 8 & 14 & 29 \\
\hline Total & 52 & 93 & 79 & 76 & 300 \\
\hline
\end{tabular}

Spearman $\mathrm{r}=0.22 ; \mathrm{p}<0.01$

Goal are specific and formulated as approach goals

Criteria 5 and 6 refer to goal formulation. Goals should be both specific (criterion 5) and formulated as an approach goal (criterion 6). Table 7 shows the mean score - in a range from 0 (not specific, avoidance goal) to 1 (specific, approach goal) - of all the goals that are formulated in the intervention plans with respect to a specific goal cluster. In general, goals are formulated rather specifically $($ mean $=0.66)$. Goals regarding addiction $($ mean $=0.83)$, education and work $($ mean $=0.74)$, finance $($ mean $=0.74)$ and friends $($ mean $=0.73)$ are found to be the most specific. Examples of specific goals include "the offender is abstinent from drugs" and "the offender has a job". Goals regarding attitude (mean =0.42), emotional well-being (mean = 0.54) and cognitive skills (mean $=0.58$ ) are the least specific. Examples of goals that are not specific include "the offender must understand his problems" and "the offender must develop his emotions and identity".

In general, probation officers use more approach goals than avoidance goals. A mean score of 1 would mean that all goals are formulated as approach goals, and a mean score of 0 would mean all goals are formulated as avoidance goals. The mean score for approach goals is 0.63 , meaning that a majority of the goals is formulated as approach goals. Goals regarding education and work (mean $=0.94)$, accommodation $($ mean $=0.90)$ and attitude $($ mean $=0.81)$ often are approach goals. Avoidance goals are often found with the criminogenic need addiction. Examples of oftenused goals on this need are "client uses no drugs" or "client controls the number of glasses he drinks in a week". 
Table 7: Mean score of goals per cluster (on a scale from 0 to 1)

\begin{tabular}{|c|c|c|c|}
\hline Goal cluster & $\begin{array}{l}\text { Number } \\
\text { goals }\end{array}$ & of specific & approach \\
\hline Accommodation & 58 & 0.69 & 0.90 \\
\hline Education/work & 112 & 0.74 & 0.94 \\
\hline Finance & 100 & 0.74 & 0.57 \\
\hline Partner/family & 50 & 0.62 & 0.76 \\
\hline Friends & 71 & 0.73 & 0.53 \\
\hline Addiction & 150 & 0.83 & 0.15 \\
\hline Emotional well-being & 119 & 0.54 & 0.75 \\
\hline Cognitive skills & 276 & 0.58 & 0.66 \\
\hline Attitude & 43 & 0.42 & 0.81 \\
\hline All goals & 979 & 0.66 & 0.63 \\
\hline
\end{tabular}

Intervention plan contains goals that are important for the offender

The final criterion for an effective intervention plan was whether offender goals are included in the intervention plan, that is, whether in the intervention plan goals are formulated about the problems that are defined by the offenders as important or as a priority in the self-assessment. The first two columns of Table 8 show how often offenders mention goals of a specific cluster as being important. Education and work, finance, relation with partner and family and cognitive skills are most mentioned as important by the offenders. It might be surprising that cognitive skills is in this list, but offenders often mention "solve my own problems" or "lose my patience" as an important problem. From the 230 offenders who filled in the self-assessment, 18 did not mention any problem or priority in the self assessment.

In the right column, Table 8 shows the match between offender goals and the goals in the intervention plan: the proportion of goals mentioned as important by the offenders that match goals in the intervention plan. This match is made on the level of goal clusters and not of the specific goals that are formulated by the offender and the probation officer. Therefore, the actual match between the specific goals of the offender and the goals in the intervention plan may be less good than this analyses implies.

The results in Table 8 indicate that offender goals often are not included in the intervention plan. Above all and again, offender goals regarding basic needs (education and work, finance and accommodation) and social relations (partner/family and friends) only match goal clusters in the intervention plan in a minority of the cases. Offender goals about addiction (match is 73\%) and cognitive skills (match is $60 \%$ ) are best addressed in the intervention plans. Offenders do not often formulate goals about attitude (only in 22 of the 230 cases), but when they do, in most cases there are no goals on attitudes in the intervention plan (match is $5 \%$ ). 
Table 8: Match between offender goals and goals in intervention plan $(N=230)$

\begin{tabular}{lllll} 
Goal cluster & $\begin{array}{l}\text { Number of } \\
\text { offenders }\end{array}$ & \multicolumn{2}{l}{ Goal intervention plan } & Match \\
& & Yes & No & \\
Addiction & 67 & 49 & 18 & $73 \%$ \\
Cognitive skills & 126 & 75 & 51 & $60 \%$ \\
Emotional well-being & 96 & 46 & 50 & $48 \%$ \\
Education/work & 139 & 64 & 75 & $46 \%$ \\
Finance & 120 & 50 & 70 & $42 \%$ \\
Accommodation & 87 & 31 & 56 & $36 \%$ \\
Friends & 89 & 28 & 61 & $31 \%$ \\
Partner/family & 105 & 29 & 76 & $28 \%$ \\
Attitude & 22 & 1 & 21 & $5 \%$ \\
\hline
\end{tabular}

Differences between high and low risk cases

Probation officers often say that in high risk cases with many criminogenic needs, they may choose to focus only on part of the assessed criminogenic needs, as addressing all of the offender's needs would ask too much of the offender. If so, with regard to the first three criteria in this study, the match in low risk cases should be better than in high risk cases because low risk offenders have fewer criminogenic needs. This was however not the case. The match between the assessed criminogenic needs and the perceived relevance of the criminogenic needs to be targeted (criterion 1) did not differ between the two groups (differences in match less than 5\%), except for the needs partner and family (16\% better match for low risk offenders) and attitude ( $10 \%$ better match for high risk offenders). Larger differences were found in the match between the assessed criminogenic needs and the goals (criterion 2). However, a substantially better match for the criminogenic needs accommodation, education and work, and finance was found for high risk offenders (14 to $28 \%$ better), and a substantially better match for low risk offenders was found for the criminogenic need friends ( $20 \%$ better). The match between the assessed criminogenic needs and the interventions is better for low risk offenders with regard to the criminogenic needs partner and family (20,7\% more 'good match'), emotional well-being (23,7\% more 'good match'), cognitive skills (19.8\% more 'good match') and attitude (29.9\% more 'good match). For high risk offenders, the match was substantially better for the criminogenic need addiction (11.2\% more 'good match'). Overall, it can not be said that the match between the assessed criminogenic needs and the intervention plans is substantially better for low risk offenders. 


\section{Discussion}

The aim of this study was to evaluate the extent to which probation officers' intervention plans for offenders that are based on an instrument for structured risk assessment actually meet the criteria for effective practice in probation. Seven criteria that can be used to evaluate intervention plans were formulated. It was found that probation officers do not systematically apply evidence-based knowledge about how to reduce recidivism and support desistance in their intervention plans. Although they often describe in their intervention plans that they want to target the (majority of the) assessed criminogenic needs, often the match between the assessed criminogenic needs and the goals on the one hand and interventions in the intervention plan on the other hand is fairly low. Also, the correlation between the assessed level of the risk of recidivism and the intensity of interventions proposed in the plan is weak. Thus, two principles of the R-N-R model (the needs principle and the risk principle) are applied insufficiently in the Dutch probation practice. Contrary to what might be expected, the use of a structured instrument for risk and needs assessment often does not result in intervention plans that have a good match to the assessed risk and needs.

It is not possible to draw general conclusions from this study about how the responsivity principle is used in intervention plans, because information about responsivity factors is often missing in the files. However, conclusions can be formulated regarding one aspect of responsivity, namely, motivating the offender and committing the offender to the intervention plan by formulating specific approach goals and by including the offender's goals in the plan. Based on this study, we conclude that the formulation of goals is fairly adequate. A majority of the goals is specific, and more approach goals than avoidance goals were found in the plans. However, offender goals are often neglected, particularly with respect to basic needs and social relationships, while improving these basic needs and social relationships were the most important goals for the offenders. The content of intervention plan seems to be determined by professional conclusions about the causes of the offending behaviour and the best way to prevent recidivism in an individual case. More than thirty years ago Bottoms and McWilliams (1979) already criticised a 'treatment' approach, in which "clients become objects of intervention rather than persons seeking help" (quotation from Raynor and Vanstone, 1994). Bottoms and McWilliams argued that one of the aims of the probation service is providing help, meaning that ultimately the offender defines what help is needed. Fifteen years later, based on the positive effects of cognitive behavioural programs on recidivism, Raynor and Vanstone proposed a combined approach in which the intervention plan is a result of dialogue and negotiation between the offender and the probation officer. Recently, the importance of involving offenders in developing intervention plans is underlined in literature about desistance. Working with an offender's goals is an important driver of change, as it can help offenders learn to govern their own lives in a pro-social way and thereby "discover agency" (McNeill 2008). Integrating offenders goals as an essential part of the intervention plan can therefore be an important improvement for the effectiveness of probation.

An important finding of this study is that intervention plans have the tendency to focus on only some criminogenic needs. The results revealed a strong emphasis on intervention plans for cognitive skills and addiction. These criminogenic needs are most commonly mentioned as relevant to being targeted, and these needs have the highest match with the goals and 
interventions in the intervention plans. Varying results are found regarding social relationships with a partner and family, emotional well-being, and attitude. When assessed as present, these criminogenic needs are often perceived as relevant and in a majority of the cases an intervention is matched, but often no goals are formulated that describe the desired change. Friends, and basic needs such as education and work, finance, and accommodation are often not included in the intervention plan, even when they are assessed to be a dynamic criminogenic need.

Taken together, the focus seems to be on improving human capital, and the improvement of social capital and basic needs is relatively neglected. This is remarkable, because, as described in the paragraph where we defined the criteria for effective intervention plans, studies regarding desistance from crime confirm that social capital is important in helping people to cease offending. Having pro-social relationships, having a stable job, and living in a pro-social neighbourhood can be essential for offenders to desist from crime (Laub and Sampson 2003; LeBel et al. 2008). Although the improvement of human capital is important and although having sufficient skills may even be a condition for handling social situations adequately, helping offenders improve their social capital is an important task for the probation service in its own right and must not be forgotten.

The findings of this study confirm conclusions that have been asserted before and that still seem valid today, namely that probation practice has a strong psychological orientation leading to a focus on individual skills (human capital) and a neglect of the social context (Farrall, 2002; Raynor and Vanstone, 1994; Smith and Vanstone, 2002). The so-called 'what works' approach certainly has influenced this focus. In the second half of the $20^{\text {th }}$ century, helping offenders was the main focus of the Dutch probation service and the character of the work was determined by a sociological orientation (Heinrich, 1995). Since the beginning of the $21^{\text {st }}$ century, the "what works' agenda was introduced in The Netherlands with a psychological orientation and emphasis on improving cognitive skills. Traditional social work methods and vocabulary disappeared, to be reintroduced again to some degree only very recently (Menger and Donker, 2012).

\section{Limitations and future directions}

In this study, we examined the intervention plans that were developed based on structured risk and needs assessment. Of course there may be differences between the intervention plan and the interventions that are actually delivered. It is possible that the practical aid or interventions that address the assessed criminogenic needs were not described in the plans, but were delivered during supervision. Moreover, even a perfect intervention plan can fail due to poor execution of the plan. For example, the intervention plan might match perfectly with the assessed risks and criminogenic needs, but if the plan is not delivered (or is delivered poorly), the intervention will likely not be effective, which can complicate the evaluation of intervention plans in terms of goal attainment or recidivism.

Studying the interventions that are actually delivered and matching them to the intervention plan might shed some light on this issue. However, probation records often lack the information that is needed for such a detailed study (Vieira et al. 2009). In the present study, it was difficult to match the assessed criminogenic needs with the interventions in the plan due to a frequent lack of detailed information regarding what was actually delivered in the interventions. Therefore, we chose to include the category "possible match" in our analyses. As a consequence, in some cases 
we may have either undervalued or overvalued the match between assessed criminogenic needs and interventions.

This study focused on the question which decisions are made by probation officers about their intervention plan. Having found that these decisions do not always follow the criteria for effective practice, it would be interesting to investigate why probation officers make these choices. On one hand, knowing and understanding their reasons may yield knowledge that can be useful and relevant for decision-making processes in probation with respect to intervention plans; on the other hand, this knowledge may also reveal inaccurate views regarding effective offender supervision that can be discussed and improved through the training or coaching of probation officers.

Deciding what interventions and practical aid should be delivered to help offenders stop reoffending is an important task for probation officers. In doing this, probation officers are supported by the development of instruments for structured risk and needs assessment and by a growing body of knowledge regarding effective offender supervision and program delivery. It seems, however, that the probation officers' match between the assessed risks and needs and the intervention plans must be improved. Providing training and/or coaching to probation officers may help improve this match, and this strategy has been effective in Canadian practice (Bonta et al. 2011). In health care, introducing a (computerized) decision-based support system has improved practitioners' performance (Garg et al. 2005). Such an approach may be an attractive option for forensic professionals as well.

Authors' note: We thank the Dutch probation service for supporting this research. We also thank Eline Eissing, Manon van Gemerden, Marjolein Huizinga and Bianca de Vries for their work on collecting information from the files, Jan Bogaard for delivering the necessary data files and Ada Andreas, Barbara Keuning and Karien Rijnen for their support in clustering the goals and interventions.

\section{References}

Andrews, D.A. and Bonta, J. (2006) The Psychology of Criminal Conduct (4th ed.). Newark, JH: LexisNexis.

Andrews, D.A. and Bonta, J. (2010) 'Rehabilitating criminal justice policy and practice.' Psychology, Public Policy, and Law 16 (1): 39-55.

Bonta, J. (2002) 'Offender risk assessment: guidelines for selection and use.' Criminal Justice and Behavior 29 (4): 355-379.

Bonta, J. and Andrews, D.A. (2010) 'Viewing offender assessment and rehabilitation through the lens of the risk-need-responsivity model.' In McNeill, F., Raynor P., and Trotter C. (Eds.) Offender supervision. New directions in theory, research and practice. Oxon: Willan Publishing. 
Bonta, J., Bourgon, G., Rugge, T., Scott, T., Yessine, A.K., Gutierrez, L., and Li, J. (2011) 'An experimental demonstration of training probation officers in evidence-based community supervision' Criminal Justice and Behavior 38 (11): 1127-1148.

Bonta, J., Rugge, T., Scott, T., Bourgon G., and Yessine, A.K. (2008) 'Exploring the black box of community supervision’ Journal of Offender Rehabilitation 47 (3): 248-270.

Bottoms, A. E., and McWilliams, W. (1979) 'A non-treatment paradigm of probation practice' British Journal of Social Work 9 (2): 159-202.

Campbell, M.A., French, S., and Gendreau, P. (2007) Assessing the utility of risk assessment tools and personality measures in the prediction of violent recidivism for adult offenders Ottawa: Department of Public Safety and Emergency Preparedness.

Coleman, J.S. (1988) 'Social capital in the creation of human capital' American Journal of Sociology 94 (suppl): s95-s120.

De Vogel, V. (2005) Structured risk assessment of (sexual) violence in forensic clinical practice. The HCR-20 and SVR-20 in Dutch forensic psychiatric patients. Thesis Universiteit van Amsterdam [University of Amsterdam]. Dutch University Press: Amsterdam.

Douglas, K.S., Webster, C.D., Hart, S.D., Eaves D., and Ogloff J.R.P. (2001) HCR-20 violence risk management companion guide. Burnaby, BC, Canada: Mental health, law, and policy institute, Simon Fraser University.

Dowden, C. and Andrews D.A. (1999) 'What works for female offenders: A meta-analytic review' Crime \& Delinquency 45 (4): 438-452.

Emmons, R.A. (1996) 'Striving and feeling. Personal goals and subjective well-being' In Gollwitzer, P.M. and Bargh, J.A. (Eds.) The psychology of action. Linking cognition and motivation to behavior. New York / London: The Guilford Press.

Farral, S. (2002) Rethinking what works with offenders. Probation, social context and desistance from crime. Cullompton: Willan Publishing.

Garg, A.X., Adhikari, N.K., McDonald, H., Rosas-Arellano, M.P., Devereaux, P.J., Beyene, J., Sam J., and Haynes R.B. (2005) 'Effects of computerized clinical decision support systems on practitioner performance and patient outcomes. A systematic review' Journal of the American Medical Association 293 (10): 1223-1238.

Grove, W.M., Zald, D.H., Lebow, Z.B.S., Snitz B.E., and Nelson C. (2000) 'Clinical versus mechanical prediction: A meta-analysis’ Psychological Assessment 12 (1): 19-30.

Hanson, R.K., Bourgon, G., Helmus L., and Hodgson S. (2009) 'The principles of effective correctional treatment also apply to sexual offenders: A meta-analysis' Criminal Justice and Behavior 36 (9): 865-891. 
Hanson, R.K., Helmus L., and Bourgon G. (2007) The validity of risk assessments for intimate partner violence: A meta-analysis Ottawa: Public Safety Canada.

Healey, K.M. (1999) Case Management in the Criminal Justice System Washington DC: U.S. Department of Justice.

Heinrich, J. P. (1995) Particuliere reclassering en overheid in Nederland sinds 1823 [Private probation and government in the Netherlands since 1823]. Arnhem: Gouda Quint.

Hildebrand, M. (2010) Handleiding RISc versie 3. Deel 1: Basisdiagnostiek, verdiepingsdiagnostiek en integrale conclusie [Manual RISc version 3. Part 1: basic assessment, in-depth assessment and integral conclusion] Utrecht: Reclassering Nederland.

Home Office (2002) Offender Assessment System OASys. User manual London: Home Office.

Jolliffe, D. and Farrington D.P. (2007) A systematic review of the national and international evidence on the effectiveness of interventions with violent offenders London: Ministry of Justice, Research Development Statistics.

Laub, J.H. and Sampson R.J. (2003) Shared beginnings, divergent lives. Delinquent boys to age 70 Cambridge, Massachusetts: Harvard University Press.

LeBel, T.P., Burnett, R., Maruna S., and Bushway S. (2008) 'The 'chicken and egg' of subjective and social factors in desistance from crime' European Journal of Criminology 5 (2): 131-159.

Locke, E.A. and Kristof, A.L. (1996) 'Volitional choices in the goal achievement process' In Gollwitzer, P.M. and Bargh, J.A. (Eds.) The psychology of action. Linking cognition and motivation to behavior. New York / London: The Guilford Press.

Locke, E.A. and Latham G.P. (2002) 'Building a practically useful theory of goal setting and task motivation. A 35-year odyssey’ American Psychologist 57 (9): 705-717.

Lowenkamp, C.T., Latessa E.J., and Holsinger A.M. (2006) 'The risk principle in action: What have we learned form 13,676 offender and 97 correctional programs?' Crime \& Delinquency 52: 77-93.

Mann, R.E., Webster, S.D., Schofield C., and Marshall W.L. (2004) 'Approach versus avoidance goals in relapse prevention with sexual offenders' Sexual abuse: A journal of research and treatment 16 (1): 65-75.

Maruna, S. and LeBel T.P., (2010) 'The desistance paradigm in correctional practice: from programmes to lives' In McNeill, F., Raynor P., and Trotter C. (Eds.) Offender supervision. New directions in theory, research and practice Oxon: Willan Publishing.

McNeill, F. (2008) Towards effective practice in offender supervision Glasgow: The Scottish Centre for Crime \& Justice Research. 
McNeill, F. and Weaver B. (2010) Changing lives? Desistance research and offender management Glasgow: The Scottish Centre for Crime \& Justice Research.

McNeill, F. and Whyte B. (2007) Reducing Reoffending. Social work and community justice in Scotland Devon: Willan Publishing.

Menger, A., and Donker, A. (2012) 'Bronnen van professionele effectiviteit. Over verantwoordelijkheid en ruimte van reclasseringswerkers [Sources of professional effectiveness. About responsibility and discretion of probation officers' Justitiële Verkenningen 38 (4): 24-42.

Raynor, P., and Vanstone, M. (1994) 'Probation practice, effectiveness and the non-treatment paradigm’ British Journal of Social Work 24 (4): 387-404.

Serin, R.C. and Lloyd C.D. (2009) 'Examining the process of offender change: The transition to crime desistance' Psychology, Crime \& Law 15 (4): 347-364.

Smith, D., and Vanstone, M. (2002) 'Probation and social justice' British Journal of Social Work 32: $815-830$.

Van der Knaap, L.M. and Alberda D.L. (2009) De predictieve validiteit van de Recidive Inschattingsschalen (RISc). [The predictive validity of the Recidivism Assessment Scales (RISc)] Den Haag: Wetenschappelijk Onderzoek- en Documentatiecentrum.

Van der Knaap, L.M., Leenarts, L.E.W., Born M.Ph., and Oosterveld P. (2010) 'Reevaluating interrater reliability in offender risk assessment' Crime \& Delinquency. (Vol. published online, doi: 10.1177/0011128710382347).

Van der Knaap, L.M., Leenarts L.E.W., and Nijssen L.T.J. (2007) Psychometrische kwaliteiten van de Recidive InschattingsSchalen (RISc). Interbeoordelaarsbetrouwbaarheid, interne consistentie en congruente validiteit [Psychometric qualities of the Recidivism Assessment Scales $(R I S c)$. Inter-rater reliability, internal consistancy and concurrent validity] Den Haag: Wetenschappelijk Onderzoek- en Documentatiecentrum.

Vieira, T.A., Skilling T.A., and Peterson-Badali M. (2009) 'Matching court-ordered services with treatment needs: Predicting treatment success with young offenders' Criminal Justice and Behavior 36 (4): 385-401.

Ward, T. and Maruna S. (2007) Rehabilitation London / New York: Routledge. 